\title{
Oncological and functional outcomes of 722 robot-assisted radical prostatectomy (RARP) cases: The largest Canadian 5-year experience
}

\author{
Côme Tholomier;, Marc Bienz; ${ }^{*}$ Pierre-Alain Hueber, MD, PhD; ${ }^{*}$ Quoc Dien Trinh, MD, FRCSC;, \\ Assaad El Hakim, MD, FRCSC; ${ }^{\dagger}$ Naif Alhathal, MD; ${ }^{*+}$ Thierry Lebeau, MD; ${ }_{i}^{\dagger}$ Serge Benayoun, MD; ${ }^{+}$ \\ Roger Valdivieso, MD; ; Dan Liberman, MD; Fred Saad, MD, FRCSC; ${ }^{*}$ Jean-Baptiste Lattouf, MD, FRCSC;* \\ Hugues Widmer, MD; Louis Begin, MD; ${ }^{\xi}$ Mathieu Latour, MD; $;$ Kevin C. Zorn, MD, FRCSC ${ }^{*}$
}

\begin{abstract}
*Section of Urology, Department of Surgery, Centre Hospitalier de l'Université de Montréal, Montréal, QC; † Division of Robotic Urology, Department of Surgery, Hopital du Sacre Coeur de Montreal, Montreal, QC; §Department of Pathology, Centre Hospitalier de I'Universite de Montreal, Montreal, QC
\end{abstract}

Cite as: Can Urol Assoc J 2014;8(5-6):195-201. http://dx.doi.org/10.5489/cuaj.2016 Published online June 16, 2014.

\section{Abstract}

Introduction: While RARP (robotic-assisted radical prostatectomy) has become the predominant surgical approach to treat localized prostate cancer, there is little Canadian data on its oncological and functional outcomes. We describe the largest RARP experience in Canada.

Methods: Data from 722 patients who underwent RARP performed by 7 surgeons (AEH performed 288, TH 69, JBL 23, SB 17, HW 15, QT 7, and KCZ 303 patients) were collected prospectively from October 2006 to December 2013. Preoperative characteristics, as well as postoperative surgical and pathological outcomes, were collected. Functional and oncological outcomes were also assessed up to 72 months postoperative.

Results: The median follow-up (Q1-Q3) was 18 months (9-36). The D'Amico risk stratification distribution was 31\% low, 58\% intermediate and $11 \%$ high-risk. The median operative time was 178 minutes (142-205), blood loss was $200 \mathrm{~mL}$ (150-300) and the postoperative hospital stay was 1 day (1-23). The transfusion rate was only $1.0 \%$. There were $0.7 \%$ major (Clavien III-IV) and $10.1 \%$ minor (Clavien I-II) postoperative complications, with no mortality. Pathologically, 445 men (70\%) were stage pT2, of which 81 (18\%) had a positive surgical margin (PSM). In addition, 189 patients (30\%) were stage pT3 and 87 (46\%) with PSM. Urinary continence (0-pads/day) returned at 3, 6, and 12 months for $68 \%, 80 \%$, and $90 \%$ of patients, respectively. Overall, the potency rates (successful penetration) for all men at 6,12 , and 24 months were $37 \%, 52 \%$, and $59 \%$, respectively. Biochemical recurrence was observed in 28 patients $(4.9 \%)$, and 14 patients $(2.4 \%)$ were referred for early salvage radiotherapy. In total, 49 patients (8.4\%) underwent radiotherapy and/or hormonal therapy.

Conclusions: This study shows similar results compared to other high-volume RARP programs. Being the largest RARP experience in Canada, we report that RARP is safe with acceptable oncologic outcomes in a Canadian setting.

\section{Introduction}

Prostate cancer is the most frequently diagnosed cancer in Canadian men, with an incidence of 104 cases/100 000 per year, and with an estimated 23600 newly cases diagnosed in $2013 .{ }^{1}$ In the United States, robotic-assisted radical prostatectomy (RARP) has gained increasing importance in the surgical management of prostate cancer since its first implementation in $2001 .^{2}$ In $2009,61 \%$ of these procedures were robotically assisted and in 2013, 69\% to $85 \%$ of prostatectomies were performed robotically, and a minority by radical retropubic prostatectomy (RRP), perineal prostatectomy (PR) or laparoscopic radical prostatectomy (LRP). ${ }^{3}$ In Canada, however, the shift in prostatectomy practice and the growing interest for RARP is more recent, with only 20 active daVinci systems in 2013.

Robotic surgery provides certain inherent advantages, including high definition 3-D vision, magnification, tremor filtration, movement scaling, and wristed instrumentation with 6 -degrees of freedom. ${ }^{4}$ These features refine the surgeon's dexterity, especially when working in a narrow space like the male pelvis during radical prostatectomy, all with the benefits of pneumoperitoneum to reduce blood loss.

Urinary incontinence and erectile dysfunction are the most common and bothersome side effects following prostatectomy. ${ }^{5}$ Recent meta-analyses have shown superior functional outcomes associated with RARP, in addition to the advantages associated with minimally invasive surgery; there are also equivalent oncological outcomes when comparing RARP to open or laparoscopic prostatectomy. ${ }^{6,7}$ Unfortunately, very few Canadian centres have reported functionnal and/or oncological outcomes of RARP since most radical prostatectomies were performed with the traditional open technique. ${ }^{8}$ The only published Canadian RARP series are by Pautler and colleagues ${ }^{9}$ from Western 
Tholomier et al.

University in London, Ontario $(\mathrm{n}=305)$ and $\mathrm{Al}-\mathrm{Hathal}$ and colleagues $^{10}$ from our group $(n=250)$. The purpose of this study is to expand the Canadian robotic prostatectomy literature by reporting an even larger, multi-surgeon experience of RARP with a complete account of functional and oncological outcomes, along with peri- and postoperative complications.

\section{Methods}

Between October 2006 and October 2013, 722 RARP were performed by 7 surgeons, in 2 teaching hospitals of the University of Montreal (KCZ performed 303, AEH 288, TH 69, JBL 23, SB 17, HW 15, and QT 7), each with a minimum experience of 200 cases during their specific roboticfellowship training. Preoperative and perioperative data, as well as surgical outcomes and pathological parameters, were collected. Follow-up prostate-specific antigen (PSA), erectile dysfunction and continence were also encompassed in a comprehensive database. Follow-up was conducted by the same surgeon at 1, 3, 6, 9, 12 months, and then at regular intervals up to 6 years. Data were prospectively collected for all parameters and analyzed retrospectively. Patients were not pre-selected; any patient who was a surgical candidate was offered RARP and only the patients who underwent the whole procedure were included in the study. No men had previous pelvic radiation or neo-adjuvant therapy. We include herein updated data on 250 patients previously published by our group,,$^{10}$ with 14 months of additional follow-up.

\section{Surgical technique}

We have previously reported on our RARP surgical technique. ${ }^{11-13}$ Urethral catheter was routinely removed on postoperative day $4(\mathrm{KCZ})$ or $7(\mathrm{AE}, \mathrm{SB}, \mathrm{TL})$ without cystogram.

\section{Data collection}

After institutional-review board approval, patient demographic and baseline parameters were collected, including PSA, Gleason score, clinical stage, International Prostate Symptoms Score (IPSS) and Sexual Health Inventory for Men (SHIM). Detailed intraoperative data and postoperative complications ( $<30$ days) were recorded on a standardized data collection sheet. Postoperatively, PSA values, IPSS, SHIM and Erection Hardness Score (EHS) scores were collected at each visit. EHS scores are defined as follows: 1 if the penis is larger but not hard; 2 if the penis is hard but not hard enough for penetration; 3 if the penis is hard enough for penetration but not completely hard; and 4 if the penis is completely hard and fully rigid. ${ }^{14,15}$

Continence was assessed by a modified question added to IPSS score "How many pads per 24 hours on average did you use in the past month for urinary incontinence: 0 , 1 security liner, 1 pad, 2 pads, 3 pads, 4 or more pads?" We used a strict definition of 0 pads as the definition of continence for analysis.

Patients who had a preoperative SHIM score of 12 to 25 were included in the potency analysis. Potency was defined as the ability to penetrate, with a SHIM score of 17 or more (with at least a score of 3 on question number 2) and/or an EHS $\geq 3$ with or without phosphodiesterase type 5 inhibitors (PDE5-I). ${ }^{14}$ Furthermore, patients who underwent inter-fascial bilateral nerve preservation at RARP were also looked at separately.

Positive surgical margin (PSM) was defined as the presence of cancer at the inked margin. All specimens were reviewed by 1 of the 3 dedicated academic uro-pathologists.

Biochemical recurrence (BCR) was defined as a rising PSA $>0.20 \mathrm{ng} / \mathrm{mL}$ in patients who had an undetectable PSA $(<0.10 \mathrm{ng} / \mathrm{mL})$ at the first visit.

\section{Statistical analysis}

For each variable, a Shapiro-Wilk's test $(p>0.05)$ and a visual inspection of their histograms, normal Q-Q plots and box plots were used to evaluate their distribution. The IBM SPSS Statistics package (IBM Corporation, version 21, Armonk, NY) was used for analysis. Data were summarized using descriptive statistics. The median followed by the first and third quartiles (Q1-Q3) was used as a measure of central tendency, unless specified otherwise.

\section{Results}

Median patient age was 61 (56-65), median body mass index was $27.0 \mathrm{~kg} / \mathrm{m}^{2}(25.1-29.6)$, and the median follow-up was 18 months (9-36). The PSA at the time of diagnosis was $5.5 \mathrm{ng} / \mathrm{ml}(4.3-7.5)$ and the transrectal ultrasound (TRUS) prostate volume was $36 \mathrm{~mL}$ (28-46). The preoperative Gleason sum $\geq 7$ accounted for $65.4 \%$ of our cohort and clinical stage T2 to T3 for $29.6 \%$ (Table 1). Of these, 22 had missing values for clinical stage, 10 for Gleason score and many were lost follow-up. The $\mathrm{D}^{\prime}$ Amico risk stratification distribution was $31.0 \%, 58.2 \%$ and $10.8 \%$ for low-, midand high-risk groups, respectively.

The median operative time was 178 minutes (142-205) with no open or laparoscopic intervention. Estimated blood loss was $200 \mathrm{~mL}$ (150-300) and only 5 patients (0.7\%) required blood transfusion in the perioperative period. The median catheterization time was 7 days (4-7). The median hospital stay was 1 day (1-23) and $86 \%$ of patients were discharged on postoperative day 1 . In total, 400 patients $(63.0 \%)$ had bilateral nerve-sparing surgery, 114 (18.0\%) had unilateral nerve sparing and $86(13.5 \%)$ had partial nerve sparing. Only 35 patients $(5.5 \%)$ had bilateral wide excision of neurovascular bundle and thus non-nerve spar- 


\begin{tabular}{|c|c|c|c|}
\hline Variable & $\begin{array}{c}\text { Group } \\
\text { (median) }\end{array}$ & Q1-03 & Range \\
\hline Age (years) & 61 & $56-65$ & $40-76$ \\
\hline BMI & 27.0 & $25.1-29.6$ & $17.4-50.5$ \\
\hline $\begin{array}{l}\text { Preoperative PSA (ng/ } \\
\mathrm{mL} \text { ) }\end{array}$ & 5.5 & 4.3-7.5 & $0.5-68.0$ \\
\hline $\begin{array}{l}\text { TRUS prostate volume } \\
(\mathrm{mL})\end{array}$ & 36 & $28-46$ & $12-149$ \\
\hline IPSS & 6 & 3-11 & $0-35$ \\
\hline SHIM & 21 & $16-24$ & $0-25$ \\
\hline Biopsy Gleason score & $\begin{array}{l}\text { Frequency } \\
(\mathrm{n}=712)\end{array}$ & Rate & \\
\hline 6 & 246 & $34.6 \%$ & \\
\hline 7 & 411 & $57.7 \%$ & \\
\hline 8 & 43 & $6.0 \%$ & \\
\hline 9 & 12 & $1.7 \%$ & \\
\hline Clinical TNM stage & $\begin{array}{c}\text { Frequency } \\
(n=700)\end{array}$ & Rate & \\
\hline $\mathrm{T} 1 \mathrm{a} / 1 \mathrm{~b}$ & 3 & $0.4 \%$ & \\
\hline $\mathrm{T} 1 \mathrm{c}$ & 490 & $70.0 \%$ & \\
\hline $\mathrm{T} 2 \mathrm{a}$ & 186 & $26.6 \%$ & \\
\hline $\mathrm{T} 2 \mathrm{~b}$ & 17 & $2.4 \%$ & \\
\hline T3 & 4 & $0.6 \%$ & \\
\hline
\end{tabular}

ing surgery (Table 2). Indications for unilateral and bilateral nerve sparing, and wide excision were previously described by Zorn and colleagues. ${ }^{16}$

There were a total of $7(0.9 \%)$ major (Clavien-III and IV) postoperative ( $<30$ days) complications. ${ }^{14}$ All 7 patients had a fully functional recovery. There was no perioperative mortality (Table 3).

The median specimen weight was $46 \mathrm{~g}$ (38-57). On final pathology, $25.9 \%$ were non-organ confined $(\geq \mathrm{pT} 3)$. The pathological Gleason sum 7 or more accounted for $82.7 \%$, including $10.0 \%$ Gleason $8-10$. The overall PSM rate was $26.3 \%$. PSM was $18.3 \%$ in pT2 and $46.0 \%$ in pT3 disease (Table 4).

The rate of urinary continence recovery (0-pads) was $41.7 \%$ at 1 month, $68.4 \%$ at 3 months, $79.9 \%$ at 6 months, $90.4 \%$ at 12 months and $91.4 \%$ at 24 months (Table 5).

A potency analysis was conducted for all patients with the following preoperative SHIM scores (12-16, 17-21 and 22-25). The potency rates for each score category were (successful penetration with or without medication) 11.1\%, $17.7 \%$ and $28.3 \%$, respectively at 1 month; $26.2 \%, 31.4 \%$ and $50.0 \%$, respectively at 6 months; $43.3 \%, 48.5 \%$ and $66.9 \%$, respectively at 12 months; and $40.0 \%, 53.3 \%$ and $76.6 \%$, respectively at 24 months (Table 6 ).

We also considered only the patients who underwent bilateral nerve sparing surgery (SHIM score of 12-16, 17-21, and $22-25)$. Their potency rates were $20.0 \%, 18.5 \%$ and $37.0 \%$, respectively at 1 month; $33.3 \%, 35.1 \%$ and $50.0 \%$,

\begin{tabular}{|c|c|c|}
\hline Variable & Group (median) & 01-03 \\
\hline "Robot time" \pm SD (minutes) & 178 & $142-205$ \\
\hline $\begin{array}{l}\text { "Docking time" } \pm \mathrm{SD} \\
\text { (minutes) }\end{array}$ & 14 & $11-16$ \\
\hline $\begin{array}{l}\text { "Skin to skin" } \pm \text { SD (minutes) } \\
\text { "Robot time" + "Docking } \\
\text { time" }\end{array}$ & 192 & $153-221$ \\
\hline Open or lap conversion & 0 & \\
\hline Estimated blood loss \pm SD (cc) & 200 & $150-300$ \\
\hline Transfusion rate, $\mathrm{n}(\%)$ & $5 / 722(0.7 \%)$ & \\
\hline Catheterization time (days) & 7 & $4-7$ \\
\hline Hospitalization (days) & 1 & $1-1$ \\
\hline Nerve preservation & Frequency $(n=635)$ & Rate \\
\hline Bilateral NSS & 400 & $63.0 \%$ \\
\hline Unilateral NSS & 114 & $18.0 \%$ \\
\hline Partial NSS & 86 & $13.5 \%$ \\
\hline Non-NSS & 35 & $5.5 \%$ \\
\hline
\end{tabular}

respectively at 6 months; $62.5 \%, 58.8 \%$ and $72.4 \%$, respectively at 12 months; $55.6 \%, 60.0 \%$ and $84.4 \%$, respectively at 24 months (Table 7).

There were $36(6.3 \%)$ patients with a PSA that did not reach undetectable levels at first visit (PSA $<0.1 \mathrm{ng} / \mathrm{mL}$ ); 11 $(1.9 \%)$ of them had a PSA higher than $1.0 \mathrm{ng} / \mathrm{mL}$. Of the remaining patients, $28(4.9 \%)$ had biochemical recurrence

Table 3. Intra- and postoperative complications ( $<30$ days)

\begin{tabular}{|c|c|c|}
\hline $\begin{array}{l}\text { Clavien } \\
\text { classification }{ }^{14}\end{array}$ & n (\%) & \\
\hline & & Intraoperative complications \\
\hline \multirow[t]{2}{*}{ IIIb } & $\begin{array}{c}13 \\
(1.8)\end{array}$ & $\begin{array}{l}\text { Bladder/Urethral tear (6), Epigastric } \\
\text { vessels injury (3), Rectal injury (2), Small } \\
\text { bowel injury (1), Incisional hernia (1) }\end{array}$ \\
\hline & & Postoperative complications \\
\hline I & $\begin{array}{c}44 \\
(6.1)\end{array}$ & $\begin{array}{l}\text { Hematoma (9), Pain (6), Bleeding (5), } \\
\text { Hematuria (4), Constipation (4), Urine } \\
\text { retention (4), Acute renal failure (3), } \\
\text { VUA leak (3), Wound dehiscence (2), } \\
\text { Urinoma (1), Urinary leak (1), Raynaud's } \\
\text { phenomenon (1), Uretric oedema (1) }\end{array}$ \\
\hline II & $\begin{array}{c}29 \\
(4.0)\end{array}$ & $\begin{array}{l}\text { Wounds infection (10), Transfusion } \\
\text { (5), Ileus (5), Urinary tract infection (3), } \\
\text { Trocar infection (1), Epididymo-orchitis } \\
\text { (1), Fever treated with IV antibiotics } \\
\text { (1), Clot retention requiring irrigation } \\
\text { (1), Hematuria requiring irrigation (1), } \\
\text { Arrhythmia (1) }\end{array}$ \\
\hline IIIb & $\begin{array}{c}1 \\
(0.1)\end{array}$ & Incisional hernia (1) \\
\hline IVa & $\begin{array}{c}6 \\
(0.8)\end{array}$ & $\begin{array}{l}\text { Pulmonary embolism (2), Evisceration } \\
\text { (2), Myocardial infarction (2) }\end{array}$ \\
\hline V & $0(0)$ & Death (0) \\
\hline
\end{tabular}


Tholomier et al.

\begin{tabular}{|c|c|c|}
\hline Variable & Groups (median) & Q1-03 \\
\hline Prostate weight (g) & 46 & $38-57$ \\
\hline Pathology Gleason score & Frequency $(n=640)$ & Rate \\
\hline 6 & 111 & $17.3 \%$ \\
\hline 7 & 465 & $72.7 \%$ \\
\hline 8 & 40 & $6.3 \%$ \\
\hline 9 & 22 & $3.4 \%$ \\
\hline 10 & 2 & $0.3 \%$ \\
\hline Pathological staging & Frequency $(n=635)$ & Rate \\
\hline pT2a & 114 & $18.0 \%$ \\
\hline pT2b & 331 & $52.1 \%$ \\
\hline рТЗа & 157 & $24.7 \%$ \\
\hline pT3b & 32 & $5.0 \%$ \\
\hline pT4 & 1 & $0.2 \%$ \\
\hline Positive surgical margin & $168 / 638$ & $26.3 \%$ \\
\hline pT2 & $81 / 442$ & $18.3 \%$ \\
\hline pT2a & $18 / 111$ & $16.2 \%$ \\
\hline pT2b & $63 / 331$ & $19.0 \%$ \\
\hline pT3 & $87 / 189$ & $46.0 \%$ \\
\hline рT3a & $66 / 157$ & $42.0 \%$ \\
\hline pT3b & $21 / 3$ & $65.6 \%$ \\
\hline
\end{tabular}

(PSA $>0.2 \mathrm{ng} / \mathrm{mL}$ ) at median follow-up of 18 months (range: 9-24) and required either radiotherapy alone or in combination with androgen deprivation therapy (ADT). In addition, there were 14 cases $(2.4 \%)$ that were electively referred for early salvage radiotherapy for rising PSA that did not reach $0.2 \mathrm{ng} / \mathrm{mL}$. Three patients $(0.5 \%)$ with undetectable PSA levels at first visit (PSA $<0.1 \mathrm{ng} / \mathrm{mL}$ ) received radiotherapy treatment within 6 months postoperatively. In total, 49 patients $(8.4 \%)$ were treated with radiotherapy or/and ADT. We stratified these findings using the D'Amico Risk classification (Table 8). The D'Amico risk distribution of all patients was $31.0 \%$ low, $58 \%$ intermediate and $11 \%$ high risk.

\section{Discussion}

We report the largest RARP experience in Canada, with a complete account of perioperative, functional and oncological

\begin{tabular}{|c|c|c|}
\hline $\begin{array}{l}\text { Follow-up } \\
\text { (months) }\end{array}$ & 0-pad/day n (\%) & $\begin{array}{c}0 \text { to 1-security pad/day } \\
\text { n (\%) }\end{array}$ \\
\hline 1 & $235 / 564=41.7 \%$ & $317 / 564=56.2 \%$ \\
\hline 3 & $288 / 421=68.4 \%$ & $333 / 421=79.1 \%$ \\
\hline 6 & $315 / 394=79.9 \%$ & $353 / 394=89.6 \%$ \\
\hline 9 & $290 / 334=86.8 \%$ & $306 / 334=91.6 \%$ \\
\hline 12 & $284 / 314=90.4 \%$ & $293 / 314=93.3 \%$ \\
\hline 18 & $229 / 247=92.7 \%$ & $233 / 247=94.3 \%$ \\
\hline 24 & $169 / 185=91.4 \%$ & $173 / 185=93.5 \%$ \\
\hline 30 & $126 / 135=93.3 \%$ & $130 / 135=96.3 \%$ \\
\hline 36 & $99 / 108=91.7 \%$ & $102 / 108=94.4 \%$ \\
\hline 48 & $69 / 72=95.8 \%$ & $69 / 72=95.8 \%$ \\
\hline 60 & $20 / 22=90.9 \%$ & $20 / 22=90.9 \%$ \\
\hline
\end{tabular}

RARP: robot-assisted radical prostatectomy.

outcomes. The results are analyzed in comparison with the data of other Canadian and international institutions (Table 9).

In Canada, the daVinci robot was only adopted in 2004. In the context of the Canadian social healthcare system, all the systems were acquired through the aide of private donor foundations with no support from the provincial or federal governments. Thus, both the relatively recent adoption and limited availability associated with Canadian healthcare budgetary constraints underlie the paucity of the national RARP data in the current medical literature.

Urinary incontinence can be the most bothersome side effect following prostatectomy and may be an important source of anxiety for patients early on in the postoperative period. ${ }^{5,17} \mathrm{~A}$ strict definition (0-pads) was used to report the rate of urinary continence. The early continence rate at 3 months was $68.4 \%$ and improved to $90.4 \%$ at 1 year. Pautler and colleagues reported $70 \%$ no-pad use at 1 year. ${ }^{9}$ The University of Alberta group reported continence rates postRRP of $57 \%$ at 3 months, and $85 \%$ at 12 months (definition of incontinence, $>8 \mathrm{~g}$ of urine loss on pad test per day). ${ }^{18} \mathrm{In}$ another prospective study from the same group, a cohort of 239 patients was studied (172 RRP and 67 LRP). According

\begin{tabular}{lcccc}
\hline Table 6. Return of erectile function/successful penetration ( $\geq$ Grade $\mathbf{3}$ erection scale) after RARP for all patients \\
\hline \multirow{2}{*}{ Time (months) } & $\begin{array}{c}\text { Preoperative SHIM } \\
\mathbf{1 2 - 1 6}\end{array}$ & $\begin{array}{c}\text { Preoperative SHIM 17-21 } \\
\text { Preoperative SHIM >21 }\end{array}$ & All patients \\
\hline 1 & $6 / 54=11.1 \%$ & $20 / 113=17.7 \%$ & $63 / 223=28.3 \%$ & $95 / 488=19.5 \%$ \\
3 & $9 / 44=20.5 \%$ & $21 / 87=24.1 \%$ & $82 / 178=46.1 \%$ & $121 / 385=31.4 \%$ \\
6 & $11 / 42=26.2 \%$ & $27 / 86=31.4 \%$ & $87 / 174=50.0 \%$ & $139 / 374=37.2 \%$ \\
9 & $10 / 34=29.4 \%$ & $23 / 74=31.1 \%$ & $91 / 151=60.3 \%$ & $139 / 316=44.0 \%$ \\
12 & $13 / 30=43.3 \%$ & $33 / 68=48.5 \%$ & $91 / 136=66.9 \%$ & $153 / 292=52.4 \%$ \\
18 & $12 / 24=50.0 \%$ & $27 / 55=49.1 \%$ & $80 / 104=76.9 \%$ & $136 / 228=59.6 \%$ \\
24 & $6 / 15=40.0 \%$ & $24 / 45=53.3 \%$ & $59 / 77=76.6 \%$ & $101 / 170=59.4 \%$ \\
30 & $4 / 10=40.0 \%$ & $17 / 31=54.8 \%$ & $40 / 50=80.0 \%$ & $74 / 121=61.2 \%$ \\
\hline
\end{tabular}

RARP: robot-assisted radical prostatectomy; SHIM: Sexual Health Inventory for Men. 


\begin{tabular}{|c|c|c|c|c|}
\hline Time (months) & $\begin{array}{c}\text { Preoperative SHIM } \\
12-16\end{array}$ & Preoperative SHIM 17-21 & Preoperative SHIM >21 & All patients \\
\hline 1 & $5 / 25=20.0 \%$ & $15 / 81=18.5 \%$ & $57 / 154=37.0 \%$ & $83 / 305=27.2 \%$ \\
\hline 3 & $6 / 18=33.3 \%$ & $15 / 55=27.3 \%$ & $75 / 122=61.5 \%$ & $103 / 229=45.0 \%$ \\
\hline 6 & $8 / 24=33.3 \%$ & $20 / 57=35.1 \%$ & $63 / 126=50.0 \%$ & $114 / 242=47.1 \%$ \\
\hline 9 & $8 / 18=44.4 \%$ & $19 / 48=39.6 \%$ & $76 / 111=68.5 \%$ & $112 / 206=54.4 \%$ \\
\hline 12 & $10 / 16=62.5 \%$ & $30 / 51=58.8 \%$ & $76 / 105=72.4 \%$ & $126 / 203=62.1 \%$ \\
\hline 18 & $8 / 14=57.1 \%$ & $25 / 39=64.1 \%$ & $71 / 86=82.6 \%$ & $115 / 164=70.1 \%$ \\
\hline 24 & $5 / 9=55.6 \%$ & $21 / 35=60.0 \%$ & $54 / 64=84.4 \%$ & $90 / 128=70.3 \%$ \\
\hline 30 & $2 / 5=40.0 \%$ & $16 / 25=64.0 \%$ & $39 / 45=86.7 \%$ & $67 / 94=71.3 \%$ \\
\hline
\end{tabular}

RARP: robot-assisted radical prostatectomy; SHIM: Sexual Health Inventory for Men.

to the 24 -hour pad testing, $13 \%$ of RRP patients and $17 \%$ of LRP patients remained incontinent at 1 year. ${ }^{19}$ Even with a stricter definition of continence, the results reported here compare favourably, but are equivalent when compared to the results of a recent meta-analysis on urinary incontinence after RARP from high volume centres worldwide. In this comparison, the weighted mean rate of urinary continence at 12 months was $84 \%$ (69-96) using the no-pad definition. ${ }^{6}$

In the era of PSA screening, younger patients with good functional status are being diagnosed with prostate cancer. ${ }^{20}$ Therefore, all efforts are made to preserve and maximize quality of life in the postoperative period. In the current cohort, $63.0 \%$ of patients had bilateral, $18.0 \%$ unilateral and $13.5 \%$ partial nerve-sparing surgery. The potency rates were $37.2 \%$ at 6 months, $52.4 \%$ at 12 months, and $59.4 \%$ at 24 months. Coelho and colleagues performed a metaanalysis on potency after RARP from pooled literature of centres of excellence. ${ }^{21}$ The weighted mean potency rates were $61.1 \%, 71.2 \%$ and $94 \%$ at 6,12 and $>18$ months, respectively. It is worth noting that more than $75 \%$ of these patients were previously potent men (considered as SHIM

\begin{tabular}{|c|c|c|c|}
\hline D’Amico Risk & Low & Medium & High \\
\hline Radiotherapy treatment/ADT $(n=49)$ & 3 & 34 & 12 \\
\hline Rate & $6.1 \%$ & $69.4 \%$ & $24.5 \%$ \\
\hline $\begin{array}{l}\text { Mean postoperative time when } \\
\text { therapy started (months) }\end{array}$ & 44 & 16 & 11 \\
\hline BCR $(n=28)$ & 1 & 21 & 6 \\
\hline Rate & $3.6 \%$ & $75.0 \%$ & $21.4 \%$ \\
\hline $\begin{array}{l}\text { Mean postoperative time when BCR } \\
\text { diagnosed (months) }\end{array}$ & 3 & 21 & 23 \\
\hline Early salvage radiotherapy $(n=14)$ & 3 & 7 & 4 \\
\hline Rate & $21.4 \%$ & $50.0 \%$ & $28.6 \%$ \\
\hline $\begin{array}{l}\text { Mean postoperative time when } \\
\text { therapy started (months) }\end{array}$ & 44 & 19 & 8 \\
\hline PSA $>0.1$ at first visit $(n=36)$ & 5 & 20 & 11 \\
\hline Rate & $13.9 \%$ & $55.6 \%$ & $30.5 \%$ \\
\hline
\end{tabular}

ADT: androgen deprivation therapy; PSA: prostate-specific antigen; BCR: biochemical recurrence.
221). Although a higher rate of phosphodiesterase inhibitor prescription may have played a role, the main likely factors explaining this difference in potency rate may be related to patient selection, comorbidities, use and motivation of penile rehabilitation, and technical aspects of the nervesparing technique (interfascial vs. extrafascial plane, traction injury during dissection and thermal vs. athermal clip use during vascular pedicle control). ${ }^{16,22,23}$

In this study, a total of 80 postoperative complications were noted including, $1.0 \%$ major and $10.1 \%$ minor according to Clavien classification. This is comparable to Pautler and colleagues' study. They recorded 70 complications in 350 RARP cases, $7.5 \%$ major and $15.4 \%$ minor; overall, $5.2 \%$ of their cases required further intervention. ${ }^{9}$ The mean hospital stay of 1.3 days reported in our study matched large RARP series in the United States, but is lower compared to other Canadian series of LRP (3.4 days) ${ }^{24}$ and RARP ( 3 days). ${ }^{9}$ Badani and colleagues analyzed 2766 RARP procedures at a single institution. They reported an overall complication rate of $12.2 \%$, of which $0.6 \%$ were major and $11.7 \%$ minor according to Clavien classification. ${ }^{25}$

With regards to surgical pathology outcomes, the overall PSM rate was $26.3 \%$, subdivided into $18.3 \%$ for pT2 and $46.0 \%$ for $\mathrm{pT} 3$ disease. This is consistent with other Canadian reports, such as Fradet and colleagues from Quebec City. They reported an overall PSM rate of 34.5\% in $1712 \mathrm{RRP}$, with $38.1 \%$ for pT2 and $52.7 \%$ for pT3 disease. ${ }^{26}$ Similarly, Corcoran and colleagues reported a $24.4 \%$ PSM rate, with $16.5 \%$ for pT2 and $46 \%$ for pT3, in 1514 patients who underwent RRP from a combined series of the University of British Columbia and the University of Melbourne. ${ }^{27}$ In our series, the overall PSM rate was affected in part due to a higher rate of PSM observed during the initial experience and associated with the surgeon-learning curve. Furthermore, the more aggressive nerve-sparing approach adopted by some surgeons to maximize potency and continence may have also contributed to the PSM.

In contrast, Pautler and colleagues reported an overall PSM rate of $16.1 \%$ in their cohort of low- to intermediate- 
Tholomier et al.

\begin{tabular}{|c|c|c|c|c|c|c|}
\hline Technique & $\mathbf{n}$ & $\begin{array}{c}\text { Mean } \\
\text { follow-up } \\
\text { (months) }\end{array}$ & $\begin{array}{c}\text { Overall PSM rate } \\
\text { (pT2 PSM, pT3 } \\
\text { PSM) (\%) }\end{array}$ & $\begin{array}{c}\text { Intercourse at } 1 \\
\text { year }(\%)\end{array}$ & $\begin{array}{c}\text { Pad-free at } 1 \text { year } \\
(\%)\end{array}$ & $\begin{array}{l}\text { BCR at } 1 \\
\text { year }(\%)\end{array}$ \\
\hline Open & 240 & 52 & NA & NA & NA & NA \\
\hline Laparoscopic & 550 & 36 & $16.7(11.9,36.7)$ & 66 & 82 & 14 \\
\hline Laparoscopic & 70 & 12 & $21(6.1,35.1)$ & 33 (6 months) & 90 (6 months) & NA \\
\hline Laparoscopic/open & 52 & 6 & NA & NA & NA & NA \\
\hline RARP & 60 & 9 & $17(4.5,50)$ & 33 (9 months) & 76 (3 months) & NA \\
\hline RARP & 200 & 9.7 & $\begin{array}{l}10.5(5.7 \\
28.5 / 20)\end{array}$ & NA & 98 & 5 \\
\hline RARP & 722 & 18 & $26.3(18.3,46.0)$ & 52.4 & 90.4 & 2.1 \\
\hline
\end{tabular}

risk RARP, with $10.2 \%$ for pT2 and $32 \%$ for $\mathrm{pT} 3 .{ }^{9}$ In Ontario, the median province-wide PSM rate for $\mathrm{pT} 2$ disease was $33 \%$ among 43 hospitals, with RRP volumes ranging from 12 to 625 , with no differences between community and teaching hospitals. ${ }^{28} \mathrm{~A}$ group from the University of Toronto reported an overall $20.8 \%$ PSM in 1268 men who underwent RRP from 1992 to $2008 .^{29}$

It is important to note that this present experience has met the goals established by the Cancer Care Ontario guidelines on radical prostatectomy, namely PSM rate of $<25 \%$ for $\mathrm{pT} 2$ disease, a mortality rate of $<1 \%$, rectal injury rate of $<1 \%$ and blood transfusion rates of $<10 \% .^{30}$

This work has several limitations besides bias associated with a single-institution study. The fact that this is a singleinstitution experience and that the postoperative data were obtained by the use of charts could have underestimated the complications rate, mainly for minor ones (such as hematoma, hematuria or even urinary tract infections); patients could have gone to another hospital or clinic for treatment. However, most patients had access through email to their surgeon and most often communicated any adverse event for medical charting and data collection, thus favouring relatively reliable results.

\section{Conclusion}

Our results compare favourably with other global highvolume RARP centres of excellence, despite initial difficulties and the fact that we operated mostly on intermediate- to high-risk patients. To date, this represents the largest Canadian experience published, which confirms that RARP is feasible and provides favourable oncological outcomes with the benefits of reduced morbidity in the Canadian medical system.

Competing interests: Mr. Tholomier, Mr. Bienz, Dr. Hueber, Dr. El Hakim. Dr. Alhathal, Dr. Lebeau, Dr. Benayoun, Dr. Valdivieso, Dr. Liberman, Dr. Widmer, Dr. Bégin and Dr. Latour all declare no competing financial or personal interests. Dr. Saad and Dr. Lattouf are Advisory Board members for Amgen, Astellas, Janssen, Abbott, Sanofi and Bayer. They have also received research grants and honoraria from Amgen, Astellas, Janssen, Abbott, Sanofi and Bayer. They have also participated in clinical trials in the past 2 years for Amgen, Astellas, Janssen, Sanofi and Bayer. Dr. Zorn is an advisor, speaker, and proctor for Greenlight laser surgery from AMS. Dr. Trinh received honorarium from Intuitive Surgical in the past.

This paper has been peer-reviewed.

\section{References}

1. Canadian Cancer Society's Advisory Committee on Cancer Statistics. Canadian Cancer Statistics 2013. Toronto, ON: Canadian Cancer Society; 2013.

2. Abbou (C, Hoznek A, Salomon L. et al. Laparoscopic radical prostatectomy with a remote controlled robot. J Urol 2001:165(6 Pt 1):1964-6.

3. Trinh QD, Sammon J, Sun M, et al. Perioperative outcomes of robot-assisted radical prostatectomy compared with open radical prostatectomy: Results from the nationwide inpatient sample. Eur Urol 2012;61:679-85. http://dx.doi.org/10.1016/i.eururo.2011.12.027

4. Berryhill Jr R., Jhaveri J, Yadav R, et al. Robotic prostatectomy: A review of outcomes compared with laparoscopic and open approaches. Urology 2008;72:15-23. http://dx.doi.org/10.1016/j.urology.2007.12.038

5. Miller DC, Sanda MG, Dunn RL, et al. Long-term outcomes among localized prostate cancer survivors: Health-related quality-of-life changes after radical prostatectomy, external radiation, and brachytherapy. I Clin Oncol 2005;23:2772-80. http://dx.doi.org/10.1200/JC0.2005.07.116

6. Ficarra V, Novara G, Rosen RC, et al. Systematic review and meta-analysis of studies reporting urinary continence recovery after robot-assisted radical prostatectomy. Eur Urol 2012;62:405-17. http://dx.doi. org/10.1016/j.eururo.2012.05.045 
7. Rocco B, Matei DV, Melegari S, et al. Robotic vs open prostatectomy in a laparoscopically naive centre: A matched-pair analysis. BJU Int 2009;104:991-5. http://dx.doi.org/10.1111/j.1464410X.2009.08532.x

8. Grover SA, Coupal L, Zowall H, et al. The economic burden of prostate cancer in Canada: Forecasts from the Montreal Prostate Cancer Model. CMAJ 2000;162:987-92.

9. Fuller A, Pautler SE. Complications following robot-assisted radical prostatectomy in a prospective Canadian cohort of 305 consecutive cases. Can Urol Assoc J 2013;7:116-21. http://dx.doi.org/10.5489/ cuaj.11116. Epub 2012 March 2.

10. Al-Hathal N, El-Hakim A. Perioperative, oncological and functional outcomes of the first robotic prostatectomy program in Quebec: Single fellowship-trained surgeon's experience of 250 cases. Can Urol Assoc J 2013;7:326-32. http://dx.doi.org/10.5489/cuaj.319

11. Zorn KC, Widmer H, Lattouf JB, et al. Novel method of knotless vesicourethral anastomosis during robotassisted radical prostatectomy: Feasibility study and early outcomes in 30 patients using the interlocked barbed unidirectional V-LOC180 suture. Can Urol Assoc J 2011;5:188-94. http://dx.doi.org/10.5489/ cuaj.10194

12. Valdivieso RF, Hueber PA, Zorn KC, et al. Robot assisted radical prostatectomy: How I do it. Part Il: Surgical technique. Can J Urol 2013;20:7073-8.

13. Valdivieso, R.F., P.A. Hueber, and K.C. Zorn, Robot assisted radical prostatectomy: how I do it. Part I: Patient preparation and positioning. Can J Urol 2013;20:6957-61.

14. El-Hakim A, Leung RA, Richstone $L$, et al. Athermal robotic technique of prostatectomy in patients with large prostate glands (>75 g): Technique and initial results. BJU Int 2006;98:47-9. http://dx.doi. org/10.1111/i.1464-410X.2006.06252.x

15. Cappelleri JC, Bushmakin AG, Symonds T, et al. Scoring correspondence in outcomes related to erectile dysfunction treatment on a 4-point scale (SCORE-4). J Sex Med 2009;6:809-19. http://dx.doi. org/10.1111/i.1743-6109.2008.01155.x

16. Zorn KC, Gofrit ON, Steinberg GP, et al. Planned nerve preservation to reduce positive surgical margins during robot-assisted laparoscopic radical prostatectomy. J Endourol 2008;22:1303-9. http://dx.doi. org/10.1089/end.2008.0009

17. Penson DF, McLerran D, Feng $Z$, et al. 5 -year urinary and sexual outcomes after radical prostatectomy: results from the prostate cancer outcomes study. J Urol 2005;173:1701-5. http://dx.doi. org/10.1097/01.ju.0000154637.38262.3a

18. Moore KN, Truong V, Estey E, et al. Urinary incontinence after radical prostatectomy: Can men at risk be identified preoperatively? J Wound Ostomy Continence Nurs 2007;34:270-9; quiz 280-1. http:// dx.doi.org/10.1097/01.WON.0000270821.91694.56

19. Jacobsen NE, Moore KN, Estey E, et al. Open versus laparoscopic radical prostatectomy: A prospective comparison of postoperative urinary incontinence rates. J Urol 2007;177:615-9. http://dx.doi. org/10.1016/i.juro.2006.09.022

20. Pelzer AE, Tewari A, Bektic J, et al. Detection rates and biologic significance of prostate cancer with PSA less than $4.0 \mathrm{ng} / \mathrm{mL}$ : Observation and clinical implications from Tyrol screening project. Urologr 2005;66:1029-33. http://dx.doi.org/10.1016/j.urology.2005.05.025

21. Coelho RF, Chauhan S, Palmer KJ, et al. Robotic-assisted radical prostatectomy: A review of current outcomes. BJU Int 2009;104:1428-35. http://dx.doi.org/10.1111/j.1464-410X.2009.08895.x

22. Shikanov $\mathrm{S}$, Woo J, Al-Ahmadie $\mathrm{H}$, et al. Extrafascial versus interfascial nerve-sparing technique for robotic-assisted laparoscopic prostatectomy: Comparison of functional outcomes and positive surgical margins characteristics. Urology 2009;74:611-6. http://dx.doi.org/10.1016/i.urology.2009.01.092

23. Karakiewicz PI, Tanguay $S$, Kattan MW, et al. Erectile and urinary dysfunction after radical prostatectomy for prostate cancer in Quebec: A population-based study of 2415 men. Eur Urol 2004;46:188-94. http:// dx.doi.org/10.1016/..eururo.2004.04.020

24. Al-Shaiii TF, Kanaroglou N, Thoma A, et al. A cost-analysis comparison of laparoscopic radical prostatec tomy versus open radical prostatectomy: The McMaster Institute of Urology experience. Can Urol Assoc J 2010;4:237-41. hitp://dx.doi.org/10.5489/cuaj.09166

25. Badani KK, Kaul S, Menon M. Evolution of robotic radical prostatectomy: Assessment after 2766 procedures. Cancer 2007;1 10:1951-8. http://dx.doi.org/10.1002/cncr.23027
26. Mauermann J, Fradet V, Lacombe L, et al. The impact of solitary and multiple positive surgical margins on hard clinical end points in 1712 adjuvant treatment-naive pT2-4 N0 radical prostatectomy patients. Eur Urol 2013;64:19-25. http://dx.doi.org/10.1016/i.eururo.2012.08.002

27. Corcoran NM, Hovens $C M$, Metcalfe $C$, et al. Positive surgical margins are a risk factor for significant biochemical recurrence only in intermediate-risk disease. BJU Int 2012;110:821-7. http://dx.doi. org/10.1111/j.1464-410X.2011.10868.x

28. Lawrentschuk N, Evans A, Srigley J, et al. Surgical margin status among men with organ-confined (pT2) prostate cancer: A population-based study. Can Urol Assoc J 201 1;5:161-6. http://dx.doi.org/10.5489/ cuaj. 10085

29. Alkhateeb $\mathrm{S}$, Alibhailow $\mathrm{A}$, Fleshner $\mathrm{N}$, et al. Impact of positive surgical margins after radical prostatectomy differs by disease risk group. J Urol 2010;183:145-50. http://dx.doi.org/10.1016/i.juro.2009.08.132

30. Chin JL, Srigley J, Mayhew LA, et al. Guideline for optimization of surgical and pathological quality performance for radical prostatectomy in prostate cancer management: Evidentiary base. Can Urol Assoc J 2010;4:13-25. http://dx.doi.org/10.5489/cuaj.08105

31. Rabbani F, Scardino P. Time course of recovery of potency after bilateral nerve sparing radical prostatectomy. J Urol 2004;171 (Suppl):310.

32. Schover LR, Fouladi RT, Warneke CL, et al. Defining sexual outcomes after treatment for localized prostate carcinoma. Cancer 2002;95:1773-85. http://dx.doi.org/10.1002/cncr.10848

33. Guillonneau B, Cathelineau X, Doublet JD, et al. Laparoscopic radical prostatectomy: Assessment after 550 procedures. Crit Rev Oncol Hematol 2002;43:123-33. http://dx.doi.org/10.1016/S1040$8428(02) 00024-0$

34. Hoznek A, Salomon L, Olsson LE, et al. Laparoscopic radical prostatectomy. The Creteil experience. Eur Urol 2001:40:38-45. http://dx.doi.org/10.1159/000049747

35. Rassweiler J, Schulze M, Teber D, et al. Laparoscopic radical prostatectomy: Functional and oncological outcomes. Curr Opin Urol 2004; 14:75-82. http://dx.doi.org/10.1097/00042307-200403000-00005

36. Stolzenburg JU, Do M, Rabenal R, et al. Endoscopic extraperitoneal radical prostatectomy: Initial experience after 70 procedures. J Urol 2003;169:2066-71. http://dx.doi.org/10.1097/01. ju. $0000067220.84015 .8 \mathrm{e}$

37. Hara I, Kawabata G, Miyake $\mathrm{H}$, et al. Comparison of quality of life following laparoscopic and open prostatectomy for prostate cancer. J Urol 2003;169:2045-8. http://dx.doi.org/10.1097/01. ju.0000063961.99940.6c

38. Ahlering TE, Woo D, Eichel $L$, et al. Robot-assisted versus open radical prostatectomy: a comparison of one surgeon's outcomes. Urology 2004;63:819-22. http://dx.doi.org/10.1016/j.urology.2004.01.038

39. Patel VR, Tully AS, Holmes $R$, et al. Robotic radical prostatectomy in the community setting-the learning curve and beyond: Initial 200 cases. J Urol 2005;174:269-72. http://dx.doi.org/10.1097/01. ju. 0000162082.12962 .40

40. Bentas W, Wolfram M, Jones J, et al. Robotic technology and the translation of open radical prostatectomy to laparoscopy: The early Frankfurt experience with robotic radical prostatectomy and one year follow-up. Eur Urol 2003;44:175-81

41. Menon $M$, Tewari A, Baize B, et al. Prospective comparison of radical retropubic prostatectomy and robotassisted anatomic prostatectomy: The Vattikuti Urology Institute experience. Urology 2002;60:864-8. http://dx.doi.org/10.1016/S0090-4295(02)01881-2

42. Tewari A, Kaul S, Menon M. Robotic radical prostatectomy: A minimally invasive therapy for prostate cancer. Curr Urol Rep 2005;6:45-8. http://dx.doi.org/10.1007/s1 1934-005-0066-6

43. Kaul S, Savera A, Badani K, et al. Functional outcomes and oncological efficacy of Vattikuti Institute prostatectomy with Veil of Aphrodite nerve-sparing: An analysis of 154 consecutive patients. BJU Int 2006;97:467-72. http://dx.doi.org/10.1111/j.1464-410X.2006.05990.x

Correspondence: Dr. Kevin Zorn, University of Montréal Hospital Centre, 235 Boul. Rene Levesque East, Suite 301, Montréal, QC H2X 1N8; zorn.chumurology@gmail.com 